\title{
Effect of submaximal exercise on fibrinolytic activity in ischaemic heart disease
}

\author{
Purshottam K. Khanna, Hari Nath Seth, V. Balasubramanian, and R. S. Hoon \\ From the Department of Cardiology, Army Hospital, Delhi, India
}

\begin{abstract}
Fibrinolytic activity and platelet adhesiveness are normal in cases of angina pectoris and healed myocardial infarction, whereas fibrinolytic activity is diminished in acute myocardial infarction. Exercise increases fibrinolytic activity in normal people but the effect on it of submaximal exercise in patients with ischaemic heart disease is not known. Resting platelet adhesiveness and fibrinolytic activity were determined in 20 patients suffering from ischaemic heart disease and eight healthy controls. Both groups were then subjected to submaximal exercise on a motor-driven treadmill. The ST segment of the electrocardiogram and the heart rate were monitored during exercise by an on-line digital computer. Fibrinolytic activity determinations were repeated immediately after exercise. There was a significant increase in fibrinolytic response in both groups but it was significantly less in the ischaemic groups (36.2\%) compared with the controls $(55.9 \%)(P<0.01)$. The ST segment depression was $2.3 \mathrm{~mm}$ in the ischaemic group and $0.52 \mathrm{~mm}$ in controls-also a significant difference $(P<0 \cdot 01)$. There was no correlation, however, between the $S T$ change and the fibrinolytic response. $A$ diminished response in the ischaemic group may favour their predisposition to thrombotic episodes.
\end{abstract}

Imbalance in the delicate relation between coagulation and fibrinolysis may result in thrombus formation (Astrup, 1956). Diminished fibrinolytic activity and increased platelet adhesiveness predispose to thrombosis. Normal fibrinolytic activity and platelet adhesiveness have been reported in cases with angina pectoris and healed myocardial infarction, but fibrinolytic activity is diminished in acute myocardial infarction (Rojel, 1959; Sikka et al., 1967; Sinha, Ghosh, and Misra, 1960) and some fatal cases have thrombosis superimposed on atherosclerotic plaques in coronary arteries (Chandler et al., 1974; Singh et al., 1970). Fibrinolytic activity is also diminished in obesity (Shaw and MacNaughton, 1963), diabetes mellitus (Fearnley, 1965; Seth, 1973; Sikka et al., 1967), and hyperlipidaemia (Greig, 1956). Exercise, however, increases fibrinolytic activity in normal persons (Fearnley, 1965; Ogston and Fullerton, 1961), but the effect of exercise on fibrinolytic activity in patients suffering from ischaemic heart disease has not apparently been studied. This report describes the effect of submaximal exercise undertaken on a motor-driven treadmill in asymptomatic subjects with a history of ischaemic heart disease.

Received 2 Jun $=1975$.

\section{Patients and methods}

A total of 20 men aged 26 to 52 years (mean 43.5 years) with a history of ischaemic heart disease of 8-96 months' duration (mean 33 months) were studied. All were asymptomatic and a glucose tolerance test showed no evidence of diabetes mellitus. Their platelet counts were within the normal range. They had not received any treatment for two weeks before the investigations. A control group consisting of eight healthy men aged 25 to 53 years (mean 43 years) were also studied.

All subjects abstained from smoking and any exercise on the morning of the test and a pretest rest of one hour was obligatory. No alcohol was allowed for 48 hours beforehand. The test was performed in a postabsorptive state at a room temperature of $28 \pm 2{ }^{\circ} \mathrm{C}$. Before exercise $5 \mathrm{ml}$ blood was taken from an antecubital vein. The details of the exercise procedure were as previously reported from this laboratory (Balasubramanian, Khanna, and Hoon, 1975). The subjects were tested to a fixed amount of exercise on an Avionics motor-driven treadmill by multistage stress as recommended by Bruce and Hornsten (1969). The total exercise work load was calculated by the formula:

$\operatorname{Sin} \theta \times$ speed of treadmill $(\mathrm{m} / \mathrm{min}) \times$ body weight, where $\theta$ is the angle of the gradient.

The work load was computed from minute to minute, keeping the body weight of each subject in mind in such a way that all subjects performed the same work load within \pm 10 per cent. The average exercise time was 
17 minutes (range 16-18 minutes). With this amount of exercise at least 85 per cent of maximal heart rate was reached in each subject. Heart rate and ST segment depression were monitored by an on-line digital Avionic computer model 2900 . None of the subjects developed arrhythmia or angina during the test. Another sample of blood was withdrawn soon after the end of exercise.

Platelet adhesiveness was estimated from the preexercise sample of blood by the method of Easthan (1964) using adenosine diphosphate (ADP). Since the effect of exercise on platelet adhesiveness is very variable platelet adhesiveness was not estimated again after exercise. The procedure was as follows: $2 \mathrm{ml}$ blood was added to $2.4 \mathrm{mg}$ of ethylenediamine-tetra-acetic acid (EDTA) and to $2 \mathrm{mg}$ of heparin in separate polystyrene bottles and mixed in a Metabern mixer at $30 \mathrm{rev} / \mathrm{min}$. To the heparinized sample $0.04 \mathrm{ml}$ of ADP solution was added (from a stock solution of $5 \mathrm{mg}$ in $20 \mathrm{ml}$ saline) and bottles returned to the mixer. After exactly 3 minutes the ADP-treated sample was transferred to another polystyrene bottle containing $2.4 \mathrm{mg}$ EDTA. Samples were mixed for 20 minutes and platelet counts performed as soon as possible but in all cases within an hour of collection. Counts were performed in duplicate and the average taken.

The platelet adhesiveness was calculated from the following formula:

Total EDTA sample count

$$
\times \frac{\text { heperinized sample ADP count }}{\text { total EDTA sample count }}
$$

Circulatory plasminogen activator was assayed in preand post-exercise samples by the euglobulin lysis time (ELT) as described by Cash (1966). The percentage fibrinolytic response was calculated as $(A-B / A) \times 100$, where $A$ and $B$ represented the resting and postexercise euglobulin lysis time (ELT).

Resting heart rate and ST segment deviation were read by the computer and the maximal figures at the termination of exercise recorded. ST segment change from the basal as well as the fibrinolytic response were statistically analysed using Student's $t$-test.

\section{Results}

Fibrinolytic activity The mean $\pm S D$ resting ELT in the ischaemic group was $252 \pm 33.1 \mathrm{~min}$ and in the control group $240 \pm 49.1 \mathrm{~min}$ (Tables 1 and 2). There was no significant difference between the two groups. The mean percentage fibrinolytic response to exercise in the ischaemic group $(36.2 \pm 8.9 \%)$ was, however, significantly less than in the control group $(55.9 \pm 7.9 \%)$ $(P<0.01)$.

Platelet adhesiveness The mean $\pm S D$ resting platelet adhesiveness in the ischaemic group was $69.8 \pm 4.9 \%(58-76 \%)$ and in controls $70.8 \pm 2.5 \%$ $(67-76 \%$ ) (Tables 1 and 2). There was no significant difference between the two groups.
ST segment change The average \pm SD ST segment depression in the ischaemic group was $2.3 \mathrm{~mm} \pm 0.24 \mathrm{~mm}(0.8-4.0 \mathrm{~mm})$ and in the controls $0.52 \pm 0.03 \mathrm{~mm}(0-0.8 \mathrm{~mm})$ (Tables 1 and 2). These were significantly different $(P<0.01)$. There was no correlation between the ST segment depression and the fibrinolytic response in the two groups.

TABLE 1 Resting platelet adhesiveness and effect of submaximal exercise on $S T$ segment and fibrinolytic activity in ischaemic heart disease

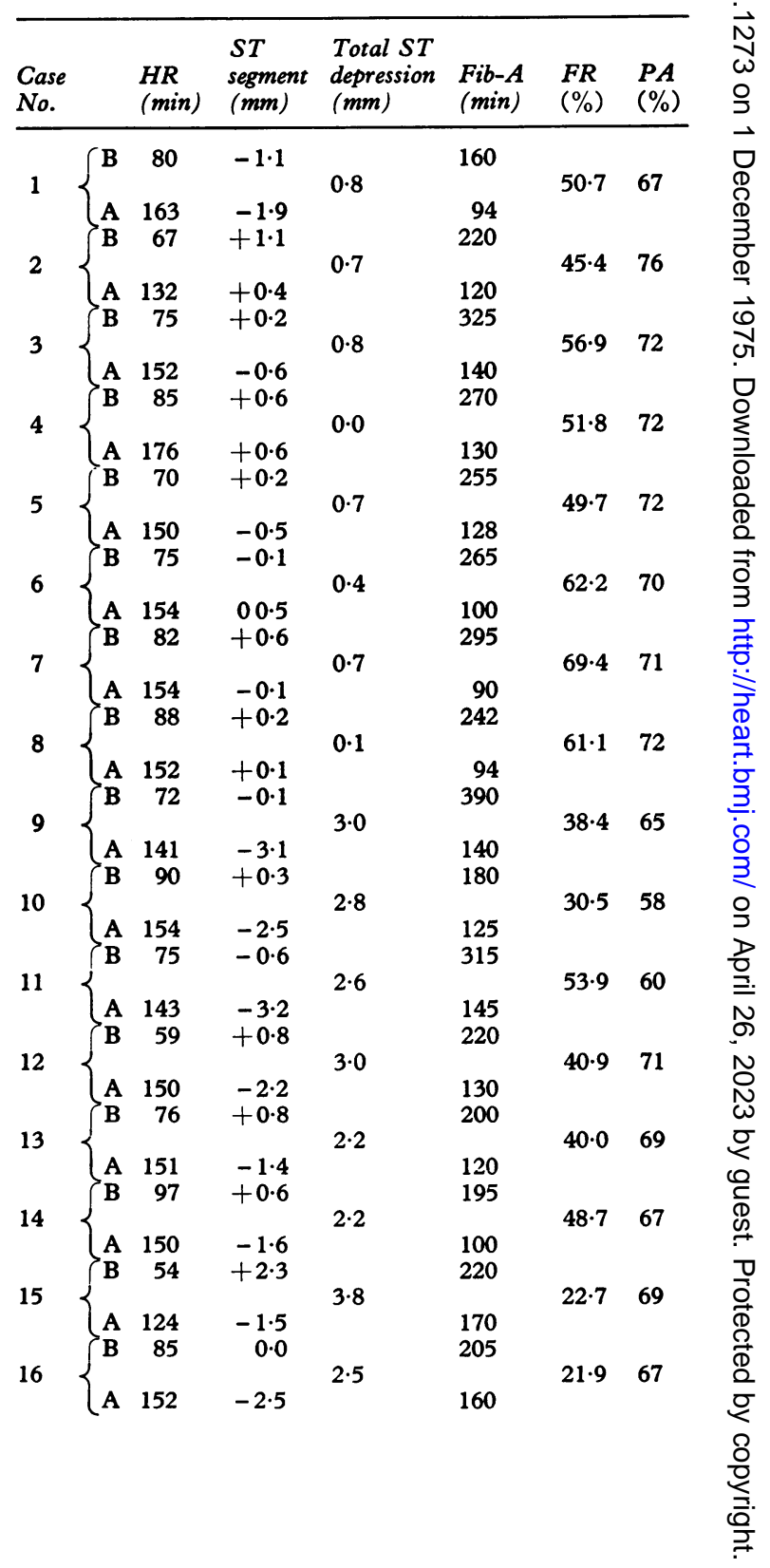


TABLE 1 Continued

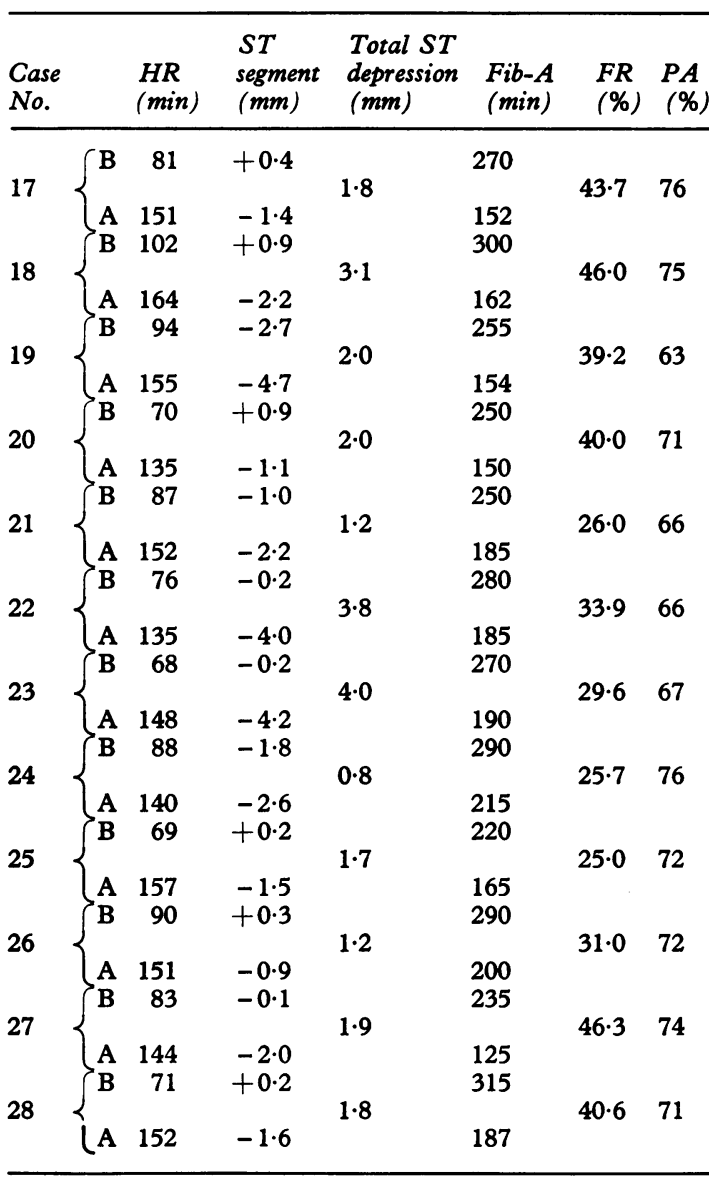

Case Nos. 1 to $8=$ normal controls; case Nos. 9 to $28=$ cases of ischaemic heart disease. $B=$ before exercise; $A=$ after exercise; $H R=$ heart rate/min; $S T-:$ below isoelectric line; ST + : above isoelectric line; $P A=$ platelet adhesiveness; Fib-A = fibrinolytic activity; $F R=$ fibrinolytic response.

\section{Discussion}

Normal platelet adhesiveness and resting fibrinolytic activity in cases of ischaemic heart disease has been described (Sinha et al., 1960). Our results are in conformity with others. Impaired fibrinolytic response to exercise indicates a state of hypercoagulability and may predispose to thrombosis.

The ELT is perhaps the best available method for assay of circulating plasminogen activator (Fearnley, 1965). Even under carefully standardized conditions the resting ELT varies from subject to subject (Blix, 1961). Despite this fluctuation, the level of ELT after a standardized exercise procedure
TABLE 2 Effect of submaximal exercise on $S T$ segment and fibrinolytic response in controls and cases with ischaemic heart disease

\begin{tabular}{llll}
\hline & Controls & Cases & Significance \\
\hline $\begin{array}{c}\text { ST segment } \\
\text { depression (mm) }\end{array}$ & $0.52 \pm 0.03$ & $2.3 \pm 0.24$ & $\mathrm{P}<0.01$ \\
$\begin{array}{c}\text { Fibrinolytic response } \\
(\%)\end{array}$ & $55.9 \pm 7.9$ & $36.2 \pm 8.9$ & $\mathrm{P}<0.01$ \\
Correlation & $\mathrm{NS}$ & $\mathrm{NS}$ & \\
\hline
\end{tabular}

NS $=$ not significant.

in the same subject appears to bear a constant relation to the basal level (Cash, 1966; Ferguson and Guest, 1974). Thus the fibrinolytic response to a fixed exercise, expressed as a percentage of preexercise level, is a reproducible phenomenon (Cash, 1966).

Exercise increases fibrinolytic activity in normal people (Fearnley, 1965; Ferguson and Guest, 1974; Ogston and Fullerton, 1961). Ogston and Fullerton (1961) showed an increase in fibrinolytic activity proportionate to the severity of exercise except in severe grades of exercise. Fibrinolytic response to exercise is diminished in diabetes (Seth, 1973), which none of our subjects had. The diminished fibrinolytic response to exercise in cases of ischaemic heart disease compared with normals found in our patients suggests proneness to thrombotic episodes.

Increased fibrinolytic activity after exercise is due to an increase of plasminogen activator. This activator arises from veins, and the increase in fibrinolytic activity is due to enhanced blood flow through them. Rest creates imbalance between fibrinolysis and coagulation in favour of the latter on the venous side of the system. Increased activator liberated on account of physical exercise may be an important prophylactic against arterial occlusion (Sherry et al., 1959). Lack of physical activity has been implicated as a factor in the aetiology of ischaemic heart disease (Morris and Crawford, 1958). Physical activity enhances fibrinolytic activity (Sherry et al., 1959) thus supporting the beneficial effects of exercise on morbidity and mortality of recurrent episodes of ischaemic heart disease (Brunner, 1968; Gottheiner, 1968; Hellerestein, 1968).

ST depression after exercise is an accepted diagnostic sign of ischaemic heart disease. The degree of depression is proportional to the severity of the obstruction in the coronary arteries. In this study no significant correlation has been established between the degree of ST segment depression and fibrinolytic response to exercise. Severity of 
occlusion to coronary blood flow and fibrinolytic response are unrelated. What determines the diminished responses in this malady with multifactorial aetiology remains to be investigated.

We are grateful to Air Marshall Ajit Nath, Director General, Armed Forces Medical Services, India, for permission to publish, and to Lieut.-General Inder Singh for his valuable criticism and guidance in preparing this paper.

\section{References}

Astrup, T. (1956). The biological significance of fibrinolysis. Lancet, 2, 565.

Balasubramanian, V., Khanna, P. K., and Hoon, R. S. (1975). On-line digital computer quantitated ST segment response to submaximal tread mill exercise. Fournal of the Association of Physicians of India, 23, 1.

Blix, S. (1961). Studies on the fibrinolytic system in the euglobulin fraction of human plasma. (a) Methodological study. (b) Application of the methods. Scandinavian Fournal of Clinical and Laboratory Investigation, 13, Suppl. $58,3$.

Bruce, R. A., and Hornsten, T. R. (1969). Exercise stress testing in evaluation of patients with ischemic heart disease. Progress in Cardiovascular Diseases, 11, 371.

Brunner, D. (1968). Active exercise for coronary patients. Rehabilitation Record, 9, 29.

Cash, J. D. (1966). Effect of moderate exercise on the fibrinolytic system in normal young men and women. British Medical fournal, 2, 502.

Chandler, A. B., Chapman, I., Erhardt, L. R., Roberts, W. C., Schwartz, C. J., Sinapius, D., Spain, D. M., Sherry, S., Ness, P. M., and Simon, T. L. (1974). Coronary thrombosis in myocardial infarction. Report of a workshop on the role of coronary thrombosis in the pathogenesis of acute myocardial infarction. American fournal of Cardiology, 34, 823.

Easthan, R. D. (1964). Rapid adhesive platelet count in whole blood. Fournal of Clinical Pathology, 17, 45.

Fearnley, G. R. (1965). Fibrinolysis. Arnold, London.
Ferguson, E. W., and Guest, M. M. (1974). Exercise, physical conditioning, blood coagulation and fibrinolysis. Thrombosis et Diathesis Haemorrhagica, 31, 63.

Gottheiner, V. (1968). Long-range strenuous sports training for cardiac reconditioning and rehabilitation. American Fournal of Cardiology, 22, 426.

Greig, H. B. W. (1956). Inhibition of fibrinolysis in alimentary lipaemia. Lancet, 2, 16.

Hellerestein, H. K. (1968). Exercise therapy in coronary disease. Bulletin of the New York Academy of Medicine, 44, 1028.

Morris, J. N., and Crawford, M. D. (1958). Coronary heart disease and physical activity of work, evidence of a national necropsy survey. British Medical fournal, 2, 1485.

Ogston, D., and Fullerton, H. W. (1961). Changes in fibrinolytic activity produced by physical activity. Lancet, $2,730$.

Rojel, J. (1959). A study of fibrinolysin activity in thrombotic diseases. Acta Medica Scandinavica, 164, 81.

Seth, H. N. (1973). Fibrinolytic response to moderate exercise and platelet adhesiveness in diabetes mellitus. Acta Diabetologica Latina, 10, 306.

Shaw, D. A., and MacNaughton, D. (1963). Relationship between blood fibrinolytic activity and body fatness. Lancet, 1, 352.

Sherry, S., Lindemeyer, R. I., Fletcher, A. P., and Alkjaersig, N. (1959). Studies of enhanced fibrinolytic activity in man. fournal of Clinical Investigation, 38, 810.

Sikka, K. K., Nath, K., Samuel, K. C., Gahlaut, D. S., Srivastava, M. C., and Gaffar, A. (1967). Plasma fibrinolytic activity in diabetes mellitus. Fournal of the Association of Physicians of India, 15, 279.

Singh, I., Khanna, P. K., Srivastava, M. C., and Hoon, R. S. (1970). Extent of possible rehabilitation of service personnel with ischaemic heart disease. British Heart fournal, 32, 665.

Sinha, B. C., Ghosh, B. P., and Misra, H. (1960) Further studies on inhibition of fibrinolysis in coronary and cerebral thombosis cases. Indian Heart fournal, 12, 197.

Requests for reprints to Lt.-Col. Purshottam K. Khanna, Department of Cardiology, Army Hospital, Delhi Cantt-10, India. 